\title{
A social work study on women's experiencing depression after childbirth
}

\author{
Nafiseh Hashemzadeh $^{a^{*}}$, Yousef Gourji ${ }^{b}$ and Gholamreza Kheirabadic
}

${ }^{a}$ MS Student, Counseling Department, Islamic Azad University of Khomeinishahr, Khomeinishahr Branch, Daneshjou Blvd, Iran

${ }^{b}$ Assistant Professor, Counseling Department, Islamic Azad University of Khomeinishahr, Khomeinishahr Branch, Daneshjou Blvd, Iran

${ }^{c}$ Assistant Prof. of Psychiatry, Behavioral Sciences Research Center, Isfahan University of Medical Sciences, Isfahan, Iran

\section{H R O N I C L E}

Article history:

Received May 20, 2013

Received in revised format

12 August 2013

Accepted 7 September 2013

Available online

September 82013

Keywords:

Pregnancy

Depression

Pregnancy type

\section{A B S T R A C T}

Many women may have some experiences on having depression after they give birth to their children. When a husband provides continuous support during his wife's pregnancy, his presence may be effective in reducing her dissatisfaction with the childbirth process. This paper presents a survey on measuring the effect of counseling programs for husbands to provide more support for their pregnant wives. The study selects a sample of 60 people from pregnant people who approached Shahid Beheshti hospital in city of Esfahan, Iran in 2012. The findings of the survey indicate that there was no relationship between women's age, educational background, infant's gender, pregnancy type and depression. However, the study detects some meaningful relationship between pregnancy type, i.e. surgery or natural, and depression ( $t$-student $=3.19$ $\alpha=0.003$ ).

\section{Introduction}

Many women suffer from depression when they give birth to their first children. Matsubayashi et al. (2004), for instance, reported that infertile women in Japan as well as in the Western world had high levels of emotional distress, anxiety, and depression. Therefore, it is important to detect essential factors influencing depression and reduce the burden of unwanted depression consequences. When a husband provides necessary support during his wife's labor, his presence normally reduces her dissatisfaction with the childbirth process. Sapkota et al. (2013) examined the effect on postnatal support, maternal anxiety and symptoms of depression experienced by new mothers in Nepal when their husband provided necessary support during labor. They reported that continuous support from a husband during his wife's labor was associated with a bigger degree of postnatal support than those who were not supported by their husband during labor. In addition, the more the women considered

*Corresponding author.

E-mail address: nafiseh.hashemzadeh@iaukhsh.ac.ir (N.Hashemzadeh) 
they were being supported, the less likely they were to experience maternal anxiety, which was associated with a lower level of depression.

Obi et al. (2009) determined the level of depression in Nigerian women following spontaneous pregnancy loss and the coping strategies implemented. They concluded that most Nigerian women suffered some level of depression following pregnancy loss, with no living children and losses. Brummelte and Galea (2010) concentrated on the association between stress, glucocorticoids and depression in humans, with a special attention on depression in women during pregnancy and postpartum and on some animal models of postpartum depression and the consequences for the offspring.

Felice et al. (2004) investigated prevalence rates and psychosocial characteristics associated with depression in pregnancy and postpartum in Maltese women and reported that the low rate of new onset postpartum depression compared with other studies could be attributable to the social support available to women living in a cohesive Catholic island community. Buultjens and Liamputtong (2007) captured the missing voices of mothers who were suffering postnatal depression. They reported that stigma was frequently attached to women who were unhappy after the birth of their child, because they were not coping with the demands of motherhood or did not instantly bond with, and love, their baby. Therefore, postnatal depression could be a terrifying and isolating experience for women. Rahman and Creed (2007) discussed the outcome of prenatal depression and risk factors associated with persistence in the first postnatal year.

\section{The proposed study}

Many women may have some experiences on having depression after they give birth to their children, which may influence their lives, significantly. When a husband provides continuous support during his wife's pregnancy, his presence may be effective in reducing her dissatisfaction with the childbirth process. This paper presents a survey on measuring the effect of counseling programs for husbands to provide more support for their pregnant wives. The study selects a sample of 60 people from pregnant people who approached Shahid Beheshti hospital in city of Esfahan, Iran in 2012.

The proposed study designs a questionnaire in Likert scale (Likert, 1932), distributes it among patients and using some statistical test, the study examines the hypotheses of the survey. There are five hypotheses associated with the study of this paper as follows,

1. There is a meaningful relationship between pregnant women's age and depression.

2. There is a meaningful relationship between pregnant women's educational backgrounds and depression.

3. There is a meaningful relationship between infant's gender and depression.

4. There is a meaningful relationship between different types of giving birth and depression.

5. There is a meaningful relationship between unexpected pregnancy and depression.

\section{The results}

In this section, we present details of our survey on testing different hypotheses of this survey.

\subsection{The relationship between age and depression}

The first hypothesis of this survey is associated with the relationship between pregnant women's age and depression. Table 1 shows the summary of testing the first hypothesis. The results of Table 1 show that there was not any meaningful relationship between women's age and depression when the 
level of significance is five or even ten percent. Therefore, the first hypothesis of this survey is not confirmed.

Table 1

The results of surveying the relationship between age and depression

\begin{tabular}{lcccccc}
\hline $\begin{array}{l}\text { Source of } \\
\text { changes }\end{array}$ & $\begin{array}{c}\text { Sum of } \\
\text { Squares }\end{array}$ & $\begin{array}{c}\text { Degree of } \\
\text { freedom }\end{array}$ & F values & P-Value & $\eta^{2}$ & $\begin{array}{c}\text { Statistical } \\
\text { power }\end{array}$ \\
\hline Women's age & 139.5 & 3 & 1.82 & .15 & 0.09 & 0.45 \\
\hline Error & 1428.833 & 56 & & & & \\
\hline
\end{tabular}

\subsection{The relationship between educational background and depression}

The second hypothesis of this survey is associated with the relationship between pregnant women's educational background and depression. Table 2 presents details of ANOVA test on the second hypothesis.

\section{Table 2}

The results of surveying the relationship between women's educational background and depression

\begin{tabular}{lcccccc}
\hline $\begin{array}{l}\text { Source of } \\
\text { changes }\end{array}$ & $\begin{array}{c}\text { Sum of } \\
\text { Squares }\end{array}$ & $\begin{array}{c}\text { Degree of } \\
\text { freedom }\end{array}$ & F values & P-Value & $\eta^{2}$ & $\begin{array}{c}\text { Statistical } \\
\text { power }\end{array}$ \\
\hline Women's age & 72.6 & 2 & 1.38 & 0.25 & 0.05 & 0.28 \\
\hline Error & 1495.72 & 57 & & & & \\
\hline
\end{tabular}

The results of Table 2 indicate that there was not any meaningful relationship between women's educational background and depression when the level of significance is five or even ten percent. Therefore, the second hypothesis of this survey is not confirmed and may conclude that education does not play important role on having depression.

\subsection{The relationship infant's gender and depression}

The third hypothesis of this survey is associated with the relationship between infant's gender and depression. Table 3 demonstrates details of t-student test on examining the third hypothesis.

Table 3

The results of surveying the relationship between infant's gender and depression

\begin{tabular}{lcccc}
\hline Variable & t-value & Degree of freedom & P-value & Mean difference \\
\hline Infant's gender & 0.07 & 58 & 0.94 & 0.09 \\
\hline
\end{tabular}

The result of Table 3 indicates that infant's gender has no impact depression when the level of significance was five or even ten percent and the third hypothesis of this survey is not confirmed.

\subsection{The relationship different types of giving birth and depression}

The fourth hypothesis of this survey is associated with the relationship between different types of giving birth and depression. Table 4 demonstrates details of t-student test on examining the fourth hypothesis.

Table 4

The results of surveying the relationship between different types of giving birth and depression

\begin{tabular}{lcccc}
\hline Variable & t-value & Degree of freedom & P-value & Mean difference \\
\hline Birth delivery & 3.19 & 58 & 0.003 & 3.92 \\
\hline
\end{tabular}


The result of Table 4 shows that different types of giving birth influence on depression when the level of significance is one percent. Our detailed survey has indicated that women giving birth through surgery are more likely to suffer from depression than others are.

\subsection{The relationship unexpected pregnancy and depression}

The last hypothesis of this survey is associated with the relationship between unexpected pregnancy and depression. Table 5 shows details of t-student test on examining the last hypothesis.

\section{Table 5}

The results of surveying the relationship between unexpected pregnancy and depression

\begin{tabular}{lcccc}
\hline Variable & t-value & Degree of freedom & P-value & Mean difference \\
\hline Unexpected pregnancy & 1.76 & 58 & 0.083 & 2.39 \\
\hline
\end{tabular}

The result of Table 5 indicates that unexpected pregnancy has no impact depression when the level of significance is five or even ten percent and the last hypothesis of this survey is not confirmed.

\section{Conclusion}

In this paper, we have presented an empirical investigation to study the effect of different factors on creating depression among women after pregnancy. The results of the survey indicated that while giving birth through surgery will more likely create depression than natural method, other factors including mothers' age, educational background, infant's gender and unexpected pregnancy did not have any impact on women's pregnancy.

\section{Acknowledgment}

The authors would like to thank the officials of Shahid Beheshti hospital for cordially cooperating on accomplishment of this survey.

\section{References}

Brummelte, S., \& Galea, L.A.M. (2010). Depression during pregnancy and postpartum: Contribution of stress and ovarian hormones. Progress in Neuro-Psychopharmacology and Biological Psychiatry, 34(5), 766-776.

Buultjens, M., \& Liamputtong, P. (2007). When giving life starts to take the life out of you: women's experiences of depression after childbirth. Midwifery, 23(1), 77-91

Felice, E., Saliba, J., Grech, V., \& Cox, J. (2004). Prevalence rates and psychosocial characteristics associated with depression in pregnancy and postpartum in Maltese women. Journal of Affective Disorders, 82(2), 297-301.

Matsubayashi, H., Hosaka, T., Izumi, S.I., Suzuki, T., Kondo, A., \& Makino, T. (2004). Increased depression and anxiety in infertile Japanese women resulting from lack of husband's support and feelings of stress. General Hospital Psychiatry, 26(5), 398-404

Obi, S.N., Onah, H.E., \& Okafor, I.I. (2009). Depression among Nigerian women following pregnancy loss. International Journal of Gynecology \& Obstetrics, 105(1), 60-62.

Rahman, A., \& Creed, F. (2007). Outcome of prenatal depression and risk factors associated with persistence in the first postnatal year: Prospective study from Rawalpindi, Pakistan. Journal of Affective Disorders, 100(1-3), 115-121

Sapkota, S., Kobayashi, T., \& Takase, M. (2013). Impact on perceived postnatal support, maternal anxiety and symptoms of depression in new mothers in Nepal when their husbands provide continuous support during labour. Midwifery, In Press. 